\title{
Ética de las biotecnologías
}

\author{
ADELA CORTINA
}

Universidad de Valencia

RESUMEN. El poder que la Nueva Genética ha puesto en manos de los seres humanos requiere una ética desde la que sea posible tomar decisiones en cuestiones de manipulación genética. El trabajo se propone (1) situar la ética de las biotecnologías en el conjunto de la bioética, (2) señalar los distintos ámbitos de la Nueva Genética que plantean problemas éticos, reconociendo que cada uno de ellos requiere un tratamiento específico, (3) esbozar un marco ético desde el que orientar las respuestas, un marco elaborado desde la ética kantiana, el enfoque de las capacidades de Sen, la ética del discurso y el principio responsabilidad de Jonas, y (4) abordar la cuestión tal vez más candente en el ámbito ético: si el poder de la manipulación genética exige poner de nuevo sobre el tapete la discusión sobre la naturaleza humana, como hacen, entre otros, Habermas y Fukuyama.
AbStRact. The power that New Genetics has placed within mankind's grasp requires ethics from which decisions on matters of genetic manipulation can be made. This work sets out to (1) place the ethics of biotechnologies in the context of bioethics as a whole; (2) point out the different spheres of New Genetics which pose ethical problems, recognising that each of these requires specific treatment; (3) outline an ethical framework to guide replies, a structure built up from Kantian ethics, Sen's capabilities approach, the ethics of discourse and Jonas' responsibility principle, and (4) to tackle what is perhaps the most burning question in the ethical sphere: if the power of genetic manipulation requires once more bringing up the discussion on human nature, as approached by Habermas and Fukuyama, amongst others.

«-Es que a mí me gustan los inconvenientes —dijo el Salvaje.

-A nosotros, no - dijo el Interventor-. Preferimos hacer las cosas con comodidad.

- Pues yo no quiero comodidad. Yo quiero a Dios, quiero poesía, quiero peligro real, quiero libertad, quiero bondad, quiero pecado.

—En suma —dijo Mustafá Mond—, usted reclama el derecho a ser desgraciado.

- Muy bien, de acuerdo — dijo el Salvaje, en tono de reto-. Reclamo el derecho a ser desgraciado.

-Esto, sin hablar del derecho a envejecer, a volverse feo e impotente, el derecho a tener sífilis y cáncer, el derecho a pasar hambre, el derecho a ser piojoso, el derecho a vivir en el temor constante de lo que puede ocurrir mañana: el derecho a coger un tifus; el derecho a ser atormentado. 
Siguió un largo silencio.

—Reclamo todos estos derechos — concluyó el Salvaje.

Mustafá Mond se encogió de hombros.

—Están a su disposición —-dijo ${ }^{1}$.

\section{ACTUALIDAD Y ESTRUCTURA DE LA GENÉTICA ${ }^{2}$}

\section{El retorno de la naturaleza humana}

La ética de las biotecnologías está de actualidad. En nuestro país los medios de comunicación sirven de plataforma permanente a los debates sobre la investigación con embriones, sobrantes de las técnicas de reproducción humana asistida o creados expresamente, y sobre la investigación con células troncales, menudean los congresos sobre el genoma humano, los encuentros sobre clonación, y el ecologismo militante se ceba en asuntos como el de los alimentos trangénicos. Sin embargo, en el debate más estrictamente filosófico el tema estrella de la GenÉtica es un tema radical, que empezó a esbozar Aldous Huxley hace más de setenta años en Un mundo feliz.

En efecto, como recuerda Francis Fukuyama en Our Posthuman Future, la generación nacida a mediados del pasado siglo leyó en dos utopías negativas la posibilidad de que el futuro fuera terrible: en Un mundo feliz de Aldous Huxley (1931) y en 1984 de George Orwell (1949) ${ }^{3}$. En la obra de Huxley se mostraba cómo el desarrollo biotecnológico podía conducir a un mundo sin envejecimiento, sin muerte, sin dolor, un mundo de individuos satisfechos con el lugar que ocupan en su sociedad, ajenos a la idea de culpa o de castigo. Un mundo, en suma, feliz, pero carente de libertad; un mundo que podría considerarse «poshumano», teniendo en cuenta que la libertad es para Occidente un rasgo decisivo de la humanidad. Por su parte, 1984 prevenía frente al riesgo de totalitarismo que podían propiciar las tecnologías de la comunicación: el Gran Hermano podría controlar el conjunto de las vidas desde una gigantesca pantalla. En ambas distopías el incremento - que no progresode las tecnologías podría conducir a un pessimum y no a un optimum. Andando el tiempo, puede decirse que la revolución de la comunicación y la información se han producido, hasta el punto de que nuestra época puede

${ }^{1}$ Aldous Huxley, Un mundo feliz, Barcelona, Plaza y Janés, 1966 (1. a ed., 1931), p. 299. Este trabajo se inscribe en el proyecto de investigación sobre éticas aplicadas BFF2001-3185-C02-01 del Ministerio de Ciencia y Tecnología.

${ }^{2}$ Utilizo la expresión «GenÉtica» para referirme al amplio campo de la ética que reflexiona sobre la Nueva Genética, de que hablamos a continuación.

${ }^{3}$ Francis Fukuyama, Our Posthuman Future. Consequences of the Biotechnology Revolution, Nueva York, Farrar, Straus and Giroux, 2002. Resulta sorprendente que un título tan expresivo del contenido de la obra como Our Posthuman Future haya sido traducido como El fin del hombre (Barcelona, Ediciones B, 2002), y que en los créditos iniciales figure como título original de la obra Posthuman Society. 
rotularse como «Era de la Información», pero sus resultados son ambiguos. Por una parte, tiene razón Fukuyama en que estas tecnologías se han puesto al servicio de la descentralización de la información y las comunicaciones, de modo que los ciudadanos se conectan entre sí con mayor facilidad que antaño. Pero, por otra parte, el control que ejercen las agencias secretas, como la CIA, no deja de tener su lado totalitario.

Sin embargo, en lo que respecta al augurio de Huxley cabe poca ambigüedad, porque las biotecnologías parecen estar sentando las bases de un mundo placentero, en el que será posible evitar un gran número de enfermedades, prolongar la edad, reforzar los caracteres hereditarios que pueden conducir a generaciones más inteligentes y bellas, incluso tal vez evitar la muerte. La gran pregunta es entonces: ¿pueden considerarse todavía «humanos» unos seres que, como los Alfa, Beta, Delta, Gamma y Épsilon de Huxley, carecen de los rasgos que históricamente hemos considerado como propios de los seres humanos? ¿Tenemos que reconocer que el Salvaje de Huxley, contrapunto de esos seres denominados con las primeras letras del alfabeto griego, es la imagen de lo propiamente humano, de la libertad que lleva aparejados sufrimiento, amor, sentido de la trascendencia, mientras que los otros, los que sólo aspiran al bienestar, no son ya seres humanos?

La posibilidad de que el futuro sea «poshumano» lleva a Fukuyama a preguntarse por lo esencial de la naturaleza humana, a poner de nuevo sobre el tapete ese viejo tema que ha ido siendo relegado paulatinamente por el mundo liberal. Pero lo verdaderamente sorprendente no es que lo aborden de nuevo autores como Fukuyama, sino también otros tan reacios a tratar sobre una posible naturaleza humana como Habermas ${ }^{4}$. Habermas ha proclamado hasta la saciedad que los nuestros son tiempos «posmetafísicos», desentendidos de cualquier pretensión de acceder a una presunta naturaleza humana. Y, sin embargo, justamente ése es el asunto que le ocupa en Die Zukunft der menschlichen Natur, el de preguntarse por la naturaleza humana, pero -eso sí- de modo «posmetafísico», porque nuestro modo moderno de entender los rasgos distintivos del ser humano en Occidente puede llegar a presentarse como una opción más entre otras. A fin de cuentas, como una «doctrina comprehensiva de bien», en el sentido del fallecido Rawls, por la que unos pueden querer optar, pero otros no. Tal vez ocurra - como decía Hans Jonas- que nos percatamos de lo que está en peligro cuando percibimos que está en peligro.

Y ¿qué es lo que está en peligro? Está en peligro al parecer la ética misma desde la que hoy en día podemos juzgar sobre la corrección o la incorrección de las técnicas concretas de manipulación genética. Está en cuestión la ética desde la que tratamos de evaluar los distintos aspectos de las técnicas de reproducción asistida, el diagnóstico preimplanatorio, la eugenesia negativa y positiva, la clonación humana y no humana, la investigación con células troncales o

${ }^{4}$ Jürgen Habermas, El futuro de la naturaleza humana. ¿Hacia una eugenesia liberal?, Barcelona, Paidós, 2002. 
los transgénicos. Está en riesgo de extinción esa ética cívica desde la que evalúan las técnicas los comités locales, nacionales y transnacionales, de suerte que se va gestando - a mi juicio- como una Ética Cívica Transnacional ${ }^{5}$. Y está en peligro porque una ética semejante hunde sus raíces en la idea moderna del respeto a la dignidad humana o, lo que es idéntico, del respeto a la libertad humana, de la que nada saben los Alfa, los Beta, los Delta, los Gamma, ni los Épsilon. Justamente, ésa es la ética de la que forma parte la Ética de las Biotecnologías, la GenÉtica, y es la que está en cuestión. Por eso en los siguientes apartados trataremos de esbozarla para pasar más tarde a enfrentar la cuestión de por qué está en peligro y por qué es preciso reflexionar de nuevo sobre la naturaleza humana, o sobre sus sucedáneos.

\section{El lugar de la GenÉtica en la Bioética Cívica Transnacional}

En el año 1970 Van Rensselaer Potter, fallecido en septiembre de 2001, publicó un artículo titulado «Bioethics, the science of survival», que, según distintas voces, abría las puertas de un nuevo saber: la bioética. El siguiente año su libro Bioethics: a Bridge to the Future precisaba los rasgos de ese saber presuntamente nuevo, que — se decía- desea tender un puente entre la cultura de las ciencias y la de las humanidades, entre los valores éticos y los hechos biológicos, con el propósito de asegurar la supervivencia de la especie humana y la mejora de la calidad de vida. Desde la perspectiva de Potter, asumida por un buen número de quienes investigan en bioética, esta forma de saber se presenta como la reflexión y acción ética sobre la vida biológica en sus diversas manifestaciones (humana, animal y vegetal) y cobra una configuración diferente a la de las éticas tradicionales, a fin de cuentas antropocéntricas, una configuración que sitúa a la vida — no sólo al ser humano- en el centro de la reflexión y la acción ${ }^{6}$.

Obviamente, la bioética de Potter surge en una época en que distintos autores reclaman una reflexión ética distinta a la tradicional, una ética ecológica, capaz de hacerse cargo de la vida amenazada. Desde la Land Ethic de Aldo Leopold, pasando por la Ecología Profunda de Arne Naess o incluso el Principio Responsabilidad de Hans Jonas, se exige una nueva ética, apta para garantizar el mantenimiento y desarrollo de la vida ${ }^{7}$.

Sin embargo, en el seno de la bioética se advierten dos tendencias al menos a la hora de interpretar su estructura y tarea, la ya mencionada de Potter

${ }^{5}$ Adela Cortina, «Bioética transnacional como quehacer público», en Bioética: un diálogo plural. Homenaje a Javier Gafo, Madrid, Universidad Pontificia Comillas, 2002, pp. 541-554.

${ }^{6}$ Van Rensselaer Potter, «Bioethics, the science of survival», Perspectives in Biology and Medicine, núm. 14, 1970, pp. 127-153; Bioethics: a Bridge to the Future, Englewood Cliffs, New Jersey, Prentice-Hall Inc., 1971; Diego Gracia, Fundamentos de bioética, Madrid, EUDEMA, 1988.

${ }^{7}$ Adela Cortina, Por una ética del consumo. La ciudadanía del consumidor en un mundo global, Madrid, Taurus, 2002, cap. VI. 
y la de Hellegers, médico que crea en Georgetown un centro de estudio de ética médica, imprimiendo a la nueva disciplina un sesgo sanitario.

A comienzos del siglo XXI ambas tendencias continúan vigentes, pero van configurando un «tercero» que consiste en considerar la bioética como una forma de reflexión y acción que contiene dos dimensiones esenciales: 1) La macrobioética, que coincide con la ética ecológica («Ecoética») y se ocupa del conjunto de la vida amenazada, tanto de las generaciones humanas actuales y futuras como del conjunto de los seres vivos, e incluso de la vida de la Tierra. 2) La microbioética, ocupada en los fenómenos de que tratan las «Ciencias de la Salud» y las biotecnologías, es decir, la Ética de la Atención Sanitaria y la GenÉtica ${ }^{8}$.

Evidentemente, entre ambas dimensiones existe una estrechísima conexión, muy especialmente porque la Ética de las Biotecnologías, la GenÉtica, tiene unas consecuencias incalculables para el futuro de la vida humana y de la vida no humana. Es justamente de esta última dimensión de la Bioética de la que nos ocupamos en este artículo, dimensión que se está gestando en el seno de una Bioética Cívica Transnacional, especialmente preocupada por las biotecnologías.

\section{La Nueva Genética}

Como afirma Juan Ramón Lacadena, en la historia de la Genética hay un antes y un después del ADN, es una historia que se puede dividir en dos lapsos de tiempo más o menos equivalentes. El nacimiento de una nueva ciencia que diera cuenta de la herencia de los caracteres biológicos habría de producirse cuando se pudiera responder a las preguntas «icuáles son las leyes por las que se transmiten los caracteres biológicos de padres a hijos?» y «icuál es la base molecular de la herencia, es decir, qué son los genes?», de ahí que pueda dividirse la historia de la Genética en los dos períodos a los que nos hemos referido: desde el año 1865, en que Mendel hizo públicos sus experimentos, relacionados con las leyes de la transmisión de los caracteres biológicos hereditarios, y 1900, año en que Hugo de Vries, Karl Correns y Erich von Tschermak-Seyseneg redescubren las leyes de Mendel, hasta 1944, y desde 1944 hasta nuestros días. Es en 1944 cuando Avery y sus colaboradores identifican el ácido desoxirribonucleico como la base molecular de la herencia, es decir, descubren que los genes son ADN, y en 1953 Watson y Crick proponen el modelo estructural de doble hélice.

Por otra parte, en la década que abarca de 1975 a 1985 se desarrolla la tecnología de los ácidos nucleicos que hace manipulables los genes. Esta posi-

${ }^{8}$ La producción en bioética en los últimos tiempos es espectacular, también en nuestro país. Una muy buena selección puede encontrarse en la bibliografía que recoge Juan Ramón Lacadena en Genética y bioética, Madrid, Universidad Pontificia Comillas/Desclée de Brouwer, 2002. 
bilidad de manipulación de los genes da lugar a lo que se ha llamado la «Nueva Genética», a esa Revolución de las Biotecnologías, tan decisiva en la historia de la humanidad como la Revolución Agrícola, la Industrial o la Informática 9 .

Evidentemente, la posibilidad de manipular los genes ha abierto la Caja de Pandora, desafiando con interrogantes de todo tipo tanto a la acción como a la reflexión. Un gran número de tales interrogantes son éticos, y tal vez podrían concretarse en los siguientes ámbitos: Manipulación genética humana, organismos modificados genéticamente y animales transgénicos. En lo que hace a la manipulación genética humana cabría considerar todavía con Lacadena los siguientes niveles: 1) Nivel molecular (análisis molecular del genoma humano (secuenciación del genoma, diagnosis preimplantacional o prenatal molecular, identificación por «huellas dactilares» del ADN) y utilización de genes humanos. 2) Manipulación de células humanas (células somáticas, células germinales, hibridación celular interespecífica, reproducción y manipulación de embriones humanos). 3) Manipulación de individuos humanos (eugenesia positiva, eugenesia negativa. 4) Manipulación de poblaciones humanas ${ }^{10}$.

A nadie se le oculta que cada uno de estos niveles, incluso cada uno de los aspectos que se contemplan en ellos, requiere un tratamiento ético específico, porque los problemas que se plantean en ellos no son en modo alguno los mismos; de ahí que la GenÉtica sea hoy uno de los ámbitos más trabajados en el conjunto de las éticas aplicadas ${ }^{11}$. Como entrar en cada uno de estos aspectos resulta imposible, intentaremos diseñar el marco ético de su tratamiento, tal como podría proponerlo una ética filosófica, atenta a su doble compromiso de fundamentar racionalmente las decisiones morales y aplicar lo ganado en el proceso de fundamentación ${ }^{12}$. El marco ético que puede estar en peligro justamente según el uso que hagamos del poder biotecnológico.

${ }^{9}$ Juan Ramón Lacadena, Genética y bioética, cap. 1.

${ }^{10}$ Ibid., pp. 21-23.

${ }^{11}$ Carlos Alonso Bedate, La ingeniería genética en la biotecnología, Cuadernos CDTI, núm. 4, 1982; José Sanmartín, Los nuevos redentores, Barcelona, Anthropos, 1987; «El desafío de la GenÉtica», en Tendencias científicas y sociales, núm. 19, 1990, pp. 8 y 9; Diego Gracia, «Problemas filosóficos de la ingeniería genética», en AAVV, Manipulación genética y moral, Madrid, Fundación Universitaria CEU, 1988, pp. 57-120; Adela Cortina, Ética aplicada y democracia radical, cap. 16; Javier Gafo, Problemas éticos de la manipulación genética, Madrid, Paulinas, 1992; Diez palabras clave en bioética, Estella, VD, 1997 (3. ${ }^{a}$ ed.); Carlos Romeo, Del gen al derecho, Universidad Externado de Colombia, Bogotá, 1996; Lydia Feito, El sueño de lo posible, Madrid, Universidad Pontificia Comillas, 1999; Javier Sádaba, La vida en nuestras manos, Barcelona, Ediciones B, 2000; Jorge Ferrer y Julio L. Martínez (eds.), Bioética: un diálogo plural, Madrid, Universidad Pontificia Comillas, 2002. Para estas cuestiones ver también la Revista de Derecho y Genoma Humano (Universidad de Deusto, Bilbao), dirigido por Carlos Romeo Casabona, y las publicaciones, editadas por Javier Gafo, de la Universidad Pontificia Comillas.

${ }^{12}$ Adela Cortina, Ética aplicada y democracia radical, Madrid, Tecnos, 1993, especialmente caps. 14-16; «El estatuto de la ética aplicada. Hermenéutica crítica de las actividades humanas», en Isegoría, núm. 13, 1996, pp. 119-134. 


\section{UN MARCO ÉTICO PARA LA GENÉTICA}

\section{1. «Manipulación»: una expresión polisémica}

La posibilidad de manipular los genes, que inaugura la Nueva Genética, plantea desde el comienzo la pregunta por el significado del término «manipulación», un término polisémico, que conviene aclarar para el asunto que nos ocupa, al menos en dos de sus acepciones.

En efecto, si acudimos al DRAE, el vocablo «manipulación» puede significar al menos dos cosas: o bien «operar con las manos o con cualquier instrumento»; o bien «intervenir con medios hábiles, y a veces arteros, en la política, en el mercado, en la información, etc., con distorsión de la verdad o la justicia, $\mathrm{y}$ al servicio de intereses particulares». En el primer caso, con el término «manipulación» nos estamos refiriendo a una intervención que puede tener cualesquiera finalidades y, por lo tanto, «manipular» significaría simplemente «intervenir». En el segundo caso, la intervención no se practica en defensa de aquel o aquellos a los que se manipula, sino en interés particular de otros grupos que salen ganando con la intervención. Precisamente por eso es preciso ocultar la verdad, no comunicar con claridad las metas que se persiguen y, por lo tanto, actuar sin el consentimiento voluntario de aquellos en quienes se interviene. En este último caso, a mi juicio, es preciso hablar de «instrumentalización».

Aclarar este doble significado es de suma utilidad porque la Bioética Cívica Transnacional, propia de sociedades con democracia liberal, se sustenta al menos sobre dos pilares que explicitaremos a continuación en su aplicación a nuestro tema: sobre el reconocimiento de la autonomía de las personas y también sobre el reconocimiento de su derecho a la autorrealización, a llevar adelante sus planes vitales, siempre que no perjudiquen los de otras personas ${ }^{13}$. De ahí que el mandato supremo de esta ética sea el de «no instrumentalizar» a los seres humanos, es decir, no intervenir en sus cuerpos, en sus mentes o en sus conductas para conducirles adonde no desean ir. El fundamento, la razón de tal derecho es el reconocimiento de la dignidad del ser humano, dignidad que exige respeto para no caer en contradicción práctica. Y justamente el respeto por la dignidad constituye el mínimo ético, el núcleo compartido por las distintas comisiones y los diversos comités en el ámbito de la GenÉtica.

Sin embargo, es preciso aclarar qué significa «respetar la dignidad de las personas», qué significa «no instrumentalizar», y muy especialmente en el caso de las biotecnologías, porque la opacidad del término puede dar lugar a interpretaciones que atentan contra el principio mismo. Para responder a esta cuestión recurriremos a la ayuda de cuatro enfoques filosóficos: al núcleo kantiano del principio de no instrumentalización, expresado en las formulaciones del

\footnotetext{
${ }^{13}$ Adela Cortina, Ética aplicada y democracia radical, cap. 8.
} 
imperativo, que es sin duda el fundamento más acabado de la dignidad humana, al enfoque de las capacidades de Amartya Sen, que puede ayudarnos a desarrollar ese núcleo porque insiste en la vertiente positiva del empoderamiento, del refuerzo de las capacidades, a la propuesta de la ética del discurso, que entiende la autonomía también como participación en un diálogo, y al principio de responsabilidad de Hans Jonas, según el cual, quien no asume el cuidado de un ser vulnerable y valioso, pudiendo hacerlo, se comporta de forma inmoral. Estos tres últimos vectores permiten desarrollar y complementar el núcleo de la ética kantiana del respeto a la dignidad, la «no instrumentalización».

\section{El núcleo ético de la GenÉtica}

Reconocer la dignidad de los seres humanos en el ámbito de la Genética $\mathrm{y}$, en consecuencia, la inmoralidad de instrumentalizarlos, exige actuar en un marco configurado por cuatro rasgos éticos.

1) En primer lugar, la humanidad tiene que ser considerada como un fin limitativo de las intervenciones científicas y técnicas. Esto significa que no cabe intervenir si con ello no se atiende a los fines de quien va a ser objeto de la manipulación, se trate de fines expresados o de fines que se le pueden suponer, sino a intereses ajenos, o a preferencias ajenas. La manipulación no puede convertirse en instrumentalización, no es moralmente justo utilizar a los seres humanos para metas ajenas a su bien, sean económicas, científicas o políticas, ni tampoco suplantarles a la hora de decidir en qué consiste su bien.

Este reconocimiento del ser humano como fin limitativo de las intervenciones plantea un buen número de problemas de envergadura, de entre los que queremos mencionar dos al menos: cuándo podemos hablar de vida personal, porque es a las personas a las que no se debe instrumentalizar, y, en segundo lugar, cuáles son los límites de la investigación biotecnológica, dado que no es lícito hacer todo lo que se puede hacer.

Un ejemplo concreto del primer problema sería el que plantea la investigación con embriones humanos. En relación con este asunto, podemos detectar un conjunto de valores y actitudes que todas las «éticas de máximos» de una sociedad comparten: el respeto a la vida humana desde la etapa de embrión, el deseo de aliviar el sufrimiento humano, la necesidad de garantizar la cualidad y seguridad del tratamiento médico, la defensa de la libertad de investigación, la defensa de la libertad de las mujeres o las parejas afectadas y, por tanto, la necesidad de pedir su consentimiento, tras una información suficiente.

Sin embargo, en el contexto actual de la bioética pueden distinguirse al menos dos tendencias en lo que respecta al tipo de respeto y protección legal que el embrión merece. Según la primera, un embrión in vitro debe protegerse como persona desde que el óvulo ha sido fecundado como ser humano, porque desde ese momento debe ser tenido como realidad personal; según la segunda tendencia, el embrión humano merece siempre especial respeto, pero, teniendo 
en cuenta que en su desarrollo pueden reconocerse etapas cualitativamente diferentes para su constitución como ser humano, el tipo de protección depende de la fase y el contexto del desarrollo ${ }^{14}$. Éste es sin duda un punto en discusión, en el que es preciso tener en cuenta razones científicas, ontológicas y éticas, que siguen siendo ampliamente debatidas.

Ante cuestiones como éstas, en torno a las que no existe acuerdo, resulta fundamental el método de abordaje. El primer paso ante una cuestión espinosa como ésta consiste en reconocer su naturaleza problemática: no es un asunto banal, no existe una única solución tan palmaria que quien se niegue a aceptarla es por ignorancia o por mala fe, existen razones que avalan posiciones diversas, por eso el fundamentalismo está de más. Están de más el fundamentalismo ideológico o religioso, pero también otros igualmente peligrosos, como el fundamentalismo de los intereses políticos o económicos, o el fundamentalismo de la propia soberbia que lleva a ciertos interlocutores a no rendirse ni ante la evidencia, una vez han lanzado una propuesta.

Una vez reconocida la naturaleza problemática del asunto en cuestión, el bioeticista de raza entiende — a mi juicio - que la única forma humana de llegar a una conclusión, siempre revisable, es entablar un diálogo entendido como una búsqueda cooperativa de lo más justo. Para lo cual resulta indispensable que todos los interlocutores asuman la posibilidad de llegar a desacuerdos razonables, es decir, la posibilidad de que con respecto a un asunto pueda haber más de una posición moralmente razonable y, por lo tanto, moralmente respetable. Como bien decía Amy Gutmann, «la tolerancia se extiende a la más vasta gama de opiniones, mientras no lleguen a las amenazas y otros daños directos y discernibles a las personas. El respeto es mucho más selectivo. Si bien no tenemos que estar de acuerdo con una posición para respetarla, debemos comprender que refleja un punto de vista moral. Por ejemplo, alguien que adopte una posición a favor del aborto debe poder comprender cómo una persona que posee seriedad moral y que carece de segundas intenciones puede oponerse a la legalización del aborto. Y en contra de dicha legalización hay serios argumentos morales. Y a la inversa» ${ }^{15}$.

Mientras los distintos miembros de un comité o de una comisión de bioética no lleguen a mantener puntos de vista moralmente razonables, mientras los miembros de ese comité no adopten la actitud de admitir que los demás pueden defender un punto de vista también razonable, aunque ellos no lo compartan, resultará imposible construir una bioética cívica. Como bien decía Javier Gafo, «los que llevamos largos años implicados en este debate (...) y en múltiples

${ }^{14}$ Carlos Alonso Bedate, «Reflexiones sobre cuestiones de vida y muerte: Hacia un nuevo paradigma de comprensión del valor ético de la entidad biológica humana en desarrollo», en F. Abel, E. Bone, J. C. Harvey (eds.), La vida humana: Origen y desarrollo, Madrid, UPC, 1989, pp. 57-81; Juan Ramón Lacadena, «Embriones humanos y cultivo de tejidos: reflexiones científicas, éticas y jurídicas», en Revista de Derecho y Genoma Humano, núm. 12, 2000, pp. 191-212.

${ }_{15}$ Amy Gutmann, «Introducción» a Charles Taylor, El multiculturalismo y «la política del reconocimiento», México, FCE, 1993, p. 40. 
foros de bioética, experimentamos que los años transcurridos no han ayudado a resolver esta cuestión ni a dar una respuesta unánime a la misma. Mi experiencia me lleva a afirmar que sería injusto descalificar como carentes de racionalidad y de sentido ético a los que consideran que el embrión preimplantatorio es una realidad respetable, pero no equiparable a la que existe más adelante en el desarrollo embrionario. De la misma manera que sería injusto calificarnos a los que extremamos el respeto a toda vida humana como anacrónicos, irracionales y oscurantistas. ¿No sería más correcto hablar de que los unos y los otros tenemos una razonabilidad, que debe respetarse mutuamente y que es inevitable en ciertos temas o tierras de penumbra, como la que acabo de indicar?» ${ }^{16}$.

En efecto, quienquiera que se adentre en el ámbito de la bioética o en cualquier otro de radical importancia humana, topará con cuestiones que distintos afectados pueden valorar de forma diferente, al menos en parte. Y no necesariamente por mala voluntad por alguna de las partes, sino también por razones como las que Rawls esgrimía al referirse al desacuerdo razonable entre personas razonables, las «cargas del juicio», que llevan a desacuerdos en el uso cívico de la razón ${ }^{17}$.

En lo que hace a la responsabilidad por las consecuencias de la manipulación, es decir, de la intervención, en la «sociedad del riesgo», se extiende no sólo a las consecuencias intencionadas, ni siquiera únicamente a las consecuencias previsibles, sino también a las consecuencias que se producen por no haber investigado suficientemente las posibilidades de daños no intencionados. En este sentido, la comunidad científica ha dado muestras de extraordinaria prudencia al proponer moratorias como la de Asilomar de 1975, y se ha desarrollado el llamado «principio de precaución», tanto desde la perspectiva ética como desde la perspectiva jurídica, aplicado sobre todo al caso de los alimentos transgénicos.

El principio de precuación consiste «en no esperar al elemento de la prueba absoluta de una relación de causa a efecto cuando elementos suficientemente serios incitan a pensar que una sustancia o una actividad cualquiera podrían tener consecuencias dañinas irreversibles para la salud o para el medio ambiente $\mathrm{y}$, por lo tanto, no son sostenibles» ${ }^{18}$. El principio no se aplica a toda situación de riesgo, sino a las que presentan dos características principales: tienen como presupuesto un contexto de incertidumbre científica, y los daños eventuales

${ }^{16}$ Javier Gafo, «¿Concebir un hijo para salvar a un hermano?», $A B C, 6$ de octubre de 2000, p. 52 .

${ }^{17}$ John Rawls, El liberalismo político, Barcelona, Crítica, 1996, pp. 85-89.

${ }^{18}$ Edwin Zaccai y Jean Noel Missa (eds.), Le principe de précaution. Signification et conséquences, Editions de l'Université de Bruxelles, 2000, 111. Ver también, entre otros, Dominique Bourg y Jean-Louis Schlegel, Parer aux risques de demain. Le principe de précaution, París, Seuil, 2001; François Ewald, Christian Gollier y Nicolas de Sadeleer, Le principe de précaution, París, PUF, 2001. 
serían graves o irreversibles ${ }^{19}$. Estas situaciones son las que contempla el principio, porque en ellas los daños potenciales son grandes, ya que la precaución es costosa social y económicamente.

Lo esencial es que la precaución no tiene sentido sino en un contexto de incertidumbre científica: exige actuar en la fuente del peligro antes de que se despeje la incertidumbre. Es imposible prever todas las consecuencias de nuestras intervenciones: el saber no engendra exclusivamente el dominio, sino también la falta de dominio y la impotencia, una ausencia de poder sobre los efectos, a medio y largo plazo, de lo que el hombre sabe hacer. Pero, por otra parte, la precaución no implica abstención, no se opone al progreso científico ni se mueve por la «heurística del temor»: precaver significa emplear todos los medios razonables para proseguir con la investigación de las posibles consecuencias de lo que puede proporcionar un beneficio a la humanidad.

2) En segundo lugar, el reconocimiento de la dignidad humana exige considerar a las personas como fin positivo de las intervenciones humanas. En este sentido es en el que Kant afirmaba que «el principio supremo de la doctrina de la virtud es el siguiente: obra según una máxima de fines tales que proponérselos pueda ser para cada uno una ley universal. Según este principio, el hombre es fin tanto para sí mismo como para los demás, y no basta con que no esté autorizado a usarse a sí mismo como medio ni a usar a los demás (con lo que puede ser también indiferente frente a ellos), sino que es en sí mismo un deber del hombre proponerse como fin al hombre en general» ${ }^{20}$.

Respetar la dignidad humana no significa únicamente no utilizar a los seres humanos como medios, tampoco significa únicamente no dañarles, sino que exige tratar de ayudarles positivamente para que puedan llevar adelante sus proyectos de autorrealización, siempre que con ello no perjudiquen a otros seres humanos ${ }^{21}$. Sólo que una afirmación semejante pone sobre el tapete, entre otras, la cuestión de la eugenesia negativa y de la eugenesia positiva, de las que hablaremos en el último apartado de este trabajo. Por el momento nos limitaremos a apuntar que en este punto el enfoque de las capacidades de Sen es de suma utilidad, porque permite aclarar qué significa «ayudar positivamente»: significa potenciar las capacidades básicas de las personas, «empoderarles» para que desarrollen sus planes de vida de acuerdo con sus proyectos de vida floreciente.

Y en este punto se plantean en relación con las biotecnologías al menos dos problemas que importa recordar. El primero de ellos se refiere a la interpretación de la «no manipulación» como «no intervención», propia del natu-

${ }^{19}$ Carlos Romeo Casabona, «Aportaciones del principio de precaución al Derecho Penal» Modernas tendencias en la ciencia del Derecho Penal y en la Criminología, Madrid, UNED, 2000, p. 81.

${ }^{20}$ Immanuel Kant, Metaphysik der Sitten, VI, 395 (trad. cast. Madrid, Tecnos, 1989, pp. 249 y 250).

${ }^{21}$ Comité de Expertos sobre Bioética y Clonación, Informe sobre clonación. En las fronteras de la vida, Madrid, Instituto de Bioética/Fundación de Ciencias de la Salud, 1999, pp. 127 y ss. 
ralismo; el segundo, al efecto paralizante que puede tener lo que Hans Jonas denominó «heurística del temor».

En efecto, la actitud bioética presta a respetar el orden de la naturaleza como orden moral tiende a interpretar la intervención biotecnológica en términos de manipulación instrumentalizadora, con lo cual prescribe abstenerse de la intervención dejando que la naturaleza siga su curso. Sin embargo, el principio de respetar la dignidad humana no sólo pretende poner límites a la intervención dañina, sino que también prescribe actuar positivamente para potenciar las capacidades de las capacidades de las personas. La cuestión no es sólo «no dañar», sino también «sí beneficiar sin dañar», poniendo los medios técnicos al servicio del desarrollo humano, con el fin de prevenir enfermedades y potenciar capacidades.

Este principio de la humanidad como fin positivo de la actuación biotecnológica exige entender la ética, no como un obstáculo, no como un freno constante de la investigación, sino todo lo contrario: el límite se perfila cuando aparece la sombra de la instrumentalización, cuando no se pretende con ella beneficiar a la persona en que se interviene, sino a otros grupos, y cuando no se cuenta con su consentimiento, actual ni potencial. En caso de que no haya instrumentalización, el principio ético es un impulso para la investigación que pueda proporcionar a los seres humanos una vida mejor.

Y en lo que hace a la heurística del temor, está plenamente justificada siempre que no sea paralizante. En este sentido es en el que hemos dicho que el principio de precaución no se opone al progreso, ni prohíbe seguir investigando, sino todo lo contrario: exige investigar las posibles consecuencias de una técnica que puede beneficiar a los seres humanos. De ahí que las moratorias deban tener un objetivo claro y asignar plazos, con todas las dificultades que ello implica.

Y de ahí, sobre todo, que las decisiones sobre tecnologías con riesgo no puedan ser tomadas sólo por los expertos, tampoco sólo por los expertos y las empresas que financian las investigaciones, tampoco únicamente por expertos, empresas y políticos, sino también por los ciudadanos que son los afectados de tales decisiones. Esta exigencia de apelar a los ciudadanos en la toma de decisiones que les afectan, más aún en condiciones de incertidumbre y riesgo, nos lleva a poner sobre el tapete un tercer lado del reconocimiento de la dignidad.

3) Reconocer la dignidad humana, no instrumentalizar a los seres humanos, exige potenciar la participación de los afectados por las decisiones biotecnológicas en esas mismas decisiones. Una de las dimensiones ineludibles de la «no instrumentalización» consiste justamente en fomentar que sean los afectados quienes tomen las decisiones en cuestiones que afectan seriamente a sus vidas y al futuro humano, porque, en caso contrario, las decisiones no podrán considerarse justas, como recuerda en nuestros días la ética del discurso.

Los sujetos éticos de las decisiones en materia de biotecnologías no pueden ser sólo los políticos, los empresarios y los científicos, por una parte, porque 
en tal caso no haríamos sino reforzar las desigualdades entre las poblaciones ricas y las pobres, entre las que pueden lograr patentes y las que dependen de ellas, pero sobre todo porque cada sujeto humano, por ser autónomo, debe poder participar en la toma de decisiones sobre cuestiones que le afectan o, al menos, debe poder ser representado en ellas. En caso contrario, se le trata como heterónomo.

De esta exigencia nace la necesidad ética del consentimiento informado, cuando se trata de casos individuales, sea un consentimiento actual o potencial ${ }^{22}$, pero también la exigencia de promover las comisiones y comités de ética que aborden los problemas desde el punto de vista de la ciudadanía.

A mi juicio, para valorar éticamente una determinada práctica, una comisión de bioética debería seguir al menos los siguientes pasos: 1) Describir en profundidad los distintos aspectos de la práctica desde el punto de vista científico. 2) Tratar de sacar a la luz y formular los valores éticos que ya comparten los distintos grupos sociales con respecto a ella. 3) Desvelar los principios éticos que orientan tales valores. 4) Indagar en la orientación de las actuaciones concretas hasta dónde es ya real el acuerdo y dónde empiezan las desavenencias. 5) Abrir un amplio debate sobre los puntos sobre los que existe desacuerdo. 6) Intentar llegar al menos al punto en que todas las posiciones parecen moralmente respetables. 7) Ofrecer recomendaciones para la actuación concreta desde la posición mayoritaria, pero dejando obviamente constancia de las discrepancias. Discrepancias que en estos casos deben ser de convicciones, no de intereses, porque el «pluralismo moral» no consiste en una diversidad de intereses que importa equilibrar, sino en una pluralidad de convicciones últimas que encuentran, sin embargo, puntos de acuerdo.

A través de este paulatino descubrimiento de valores y principios éticos compartidos desde los que enjuiciar qué tipo de prácticas son humanizadoras es posible ir sacando a la luz, frente al relativismo y al subjetivismo, una intersubjetividad ética ya existente.

Por último, potenciar la participación invita a organizar «conferencias de ciudadanos», como las que han tenido lugar en países como Francia en relación con los transgénicos ${ }^{23}$. Ampliar la información de la ciudadanía y crear plataformas para la participación es, pues, un requisito indispensable del respeto a la libertad.

4) En cuarto lugar, la GenÉtica no se ocupa únicamente de la vida humana, sino del conjunto de la vida que puede estar amenazada o puede ser potenciada por los avances técnicos. En este sentido es en el que resulta de gran ayuda el Principio Responsabilidad tal como Hans Jonas lo entiende: ante el recién nacido, débil e inerme, se sienten responsables los que tienen poder para protegerlo; ante algo que es bueno y, por tanto, debe ser, el que tiene el poder de conservarlo se siente abochornado de su egoísmo si no lo hace. Al comprobar

${ }^{22}$ Pablo Simón, El consentimiento informado, Madrid, Triacastela, 2000.

${ }^{23}$ Dominique Bourg y Jean-Louis Schlegel, op. cit., pp. 155 y ss. 
que algo es bueno en sí mismo y además vulnerable, quien tiene poder para protegerlo, para cuidar de ello, debe hacerlo, debe hacerse responsable de su suerte ${ }^{24}$. Si los seres vivos tienen un valor interno, aunque no sea absoluto, y si son vulnerables, quien pudiendo hacerse responsable de ellos no asume su responsabilidad se comporta de forma inmoral.

\section{3. ¿La autonomía en peligro? El debate de la eugenesia}

En su libro El futuro de la naturaleza humana vence Habermas su inveterada repugnancia a tratar sobre lo bueno (sobre lo que él considera «lo ético», a diferencia de «lo moral», que identifica con «lo justo»), y se aviene a abordar el asunto de la ética, pero de la ética de la especie, no de los individuos. La filosofía moral — había dicho hasta la saciedad - se ocupa sólo de la dimensión universalizable mediante argumentos del fenómeno moral, de lo justo, no de los proyectos de autorrealización de las personas concretas. Sin embargo, tal vez ocurra - como dijimos-que tomamos conciencia de lo que está en juego cuando nos percatamos de que está en juego, y lo que está en juego, gracias al poder biotecnológico, es que los seres humanos puedan seguir entendiéndose a sí mismos como seres autónomos, como autores exclusivos de su biografía única, como seres con conciencia de que determinados mandatos deberían ser universalmente cumplidos por todos aquellos que sean racionales.

Está en juego nada menos que podamos seguir teniendo por rasgos de los seres humanos la autonomía, el sentido de lo justo y la autoría de la propia vida. La especie humana corre el peligro de acabar no distinguiéndose ya por estar compuesta de seres que se reconocen recíprocamente como interlocutores válidos, capaces de decir «sí» o «no» ante un hablante, artífices de su propia vida. Es preciso, pues, abordar el asunto que puede poner en cuestión nuestra forma de comprender lo característico de la especie humana, y que no es sino el asunto de la eugenesia, que los avances biotecnológicos han puesto de nuevo sobre el tapete de la discusión ${ }^{25}$.

La percepción de la eugenesia es muy diferente en el mundo anglosajón, aun con excepciones, y en el continente europeo. En Europa la experiencia del nazismo dejó una huella profunda, una convicción difícil de superar de que nunca más debería repetirse una experiencia semejante. En el mundo anglosajón, sin embargo, las cosas se ven con mayor optimismo, desde el momento en que parece necesario distinguir entre eugenesia autoritaria y eugenesia liberal. La eugenesia practicada en la Alemania nacionalsocialista era coercitiva y estaba auspiciada por el Estado, era - por tanto- autoritaria, mientras que en el caso de una eugenesia liberal el Estado se mantendría neutral y serían

${ }^{24}$ Hans Jonas, El principio responsabilidad, Barcelona, Círculo de Lectores, 1994.

${ }_{25}$ Jeremy Rifkin llega a hablar de una «civilización eugenésica» en El siglo de la biotecnología, Barcelona, Crítica/Marcombo, 1999. 
los padres quienes promoverían unas intervenciones u otras. ¿No se trataría, en definitiva, como mantienen algunos autores, de ampliar el derecho de los padres a la educación de sus hijos al derecho a proporcionarles la mejor herencia genética a su alcance? ¿No puede decirse que entre eugenesia y educación apenas existe diferencia?

A juicio de Habermas, entre eugenesia y educación existe una profunda diferencia, porque en el caso de la educación la persona puede alzarse críticamente ante quien decidió una educación u otra, la acción es reversible, mientras que la acción eugenésica es irreversible y la persona cuya herencia se manipula no ha sido tratada como un potencial interlocutor, colocado en una situación de simetría. La clave para distinguir entre eugenesia y educación es que en el primer caso no habría acción comunicativa contrafácticamente presupuesta, en el caso de la educación se producen acciones comunicativas.

Sin embargo, de aquí no se desprende la abstención de cualquier forma de eugenesia, sino sólo de la positiva, de la eugenesia perfeccionadora. Porque, como ya comentamos, la gran pregunta de la manipulación genética humana no es si es posible éticamente intervenir, sino si es posible en las intervenciones genéticas ir más allá de la eugenesia negativa, es decir, más allá de la eugenesia terapéutica, entrando en el ambiguo terreno de la eugenesia positiva, la eugenesia de perfeccionamiento. A formular esta pregunta nos obligan aquellas dos primeras dimensiones de la «no instrumentalización» a las que nos referimos: la de la humanidad como fin limitativo y como fin positivo de las intervenciones. Dónde está el límite es siempre la gran cuestión. Y en este punto es en el que Habermas ofrece una respuesta desde la ética del discurso: hay una idea regulativa que permite trazar la frontera entre la eugenesia negativa y la positiva, la idea de un consenso con el posible afectado, supuesto al menos contrafácticamente $^{26}$.

En efecto, según Habermas, para trazar una frontera entre las eugenesias negativa y positiva es preciso tomar como modelo la frontera que existe entre dos actitudes: la del terapeuta, que actúa en virtud de un consenso futuro, presupuesto de forma contrafáctica, y la del diseñador, que adopta frente al embrión una actitud instrumentalizadora y optimizadora ${ }^{27}$. Es justamente el punto de vista moral que prescribe no instrumentalizar el que nos confirma en la lógica de la curación y nos exige trazar la frontera entre la eugenesia negativa y la perfeccionadora, porque en el primer caso tratamos al embrión como el interlocutor potencial, que un día será actual y se encontrará en una relación de simetría con el terapeuta, y podemos suponer contrafácticamente un consenso, que sólo puede darse por supuesto cuando se trata de evitar males extremos indeseables; en el caso de la eugenesia perfeccionadora, por el contrario, el diseñador trata al embrión como un objeto en el que quiere

\footnotetext{
${ }^{26}$ Ibid., p. 118.

${ }^{27}$ Ibid., p. 124.
} 
plasmar los rasgos que él considera deseables según sus particulares preferencias, programa a la persona sin contar con su conformidad virtual.

Podemos decir, recurriendo al doble sentido de «manipulación» al que aludimos al comienzo, que en el caso de la eugenesia negativa el terapeuta interviene, mientras que en el de la eugenesia positiva, el diseñador instrumentaliza según sus preferencias. Y, visto desde la teoría de la acción comunicativa, que en el primer caso se produce una acción comunicativa virtual entre sujetos, mientras que en el segundo se produce una acción instrumentalizadora entre un sujeto y una persona a la que trata como objeto.

Con ello se pone en cuestión, no una naturaleza humana entendida al modo tradicional, sino lo que Habermas llama una autocomprensión ética mínima de la especie, la moral autónoma alcanzada por la Modernidad, aquella en la que convergen las interpretaciones que las religiones hacen del mundo y del yo ${ }^{28}$. Pero, ¿es verdad esto? ¿Conduciría la eugenesia positiva al destierro de la autonomía y, con ella, del marco ético que esbozamos en el apartado anterior?

El debate no ha hecho sino empezar, las espadas están en alto y la incertidumbre impregna el futuro desde un punto de vista científico. Pero algunas cosas sí quisiera apuntar por ir dando fin a este trabajo. La aportación de Habermas es sin duda valiosísima, pero cabe dudar al menos de tres cosas.

En primer lugar, cabe dudar de que la persona que, llegada a la edad adulta, toma conciencia de que se ha intervenido humanamente en su dotación genética, se crea por ello menos apta para llevar adelante su vida de forma autónoma y menos apta para ser autora de su propia biografía, y se sienta instrumentalizada y objetivada de tal modo que no se reconozca como persona desde el reconocimiento intersubjetivo de sujetos que así le reconocen y a los que así reconoce. A pesar de la pretensión de Habermas de que la diferencia entre «lo crecido» (das Gewachsene) y «lo hecho» (das Gemachte), puede llevar a la persona «hecha» a verse disminuida en su autonomía, no parece que el descubrimiento de que en su caso la lotería natural se haya reducido lleve a una persona a perder la capacidad de regirse por leyes universalizables o de dirigir su vida por sí misma desde el reconocimiento mutuo. Nadie elige nacer, y ése no es un obstáculo a la autonomía.

En segundo lugar, la diferencia entre intervención genética y educación no es tan grande desde el punto de vista de la teoría de la acción comunicativa, porque en ambos casos se da una asimetría entre el interventor y el intervenido, de forma que en el caso de la educación también el interventor decide en solitario el tipo de educación del hijo, e influye en la conformación de su carácter de forma difícilmente reversible. En ambos casos el interventor debe suponer un consenso contrafáctico y entender que la decisión que toma podría ser aceptada en una situación de simetría, porque ha intentado lo mejor.

\footnotetext{
${ }^{28}$ Íbid., p. 60.
} 
A mi juicio, y por último, los verdaderos problemas se plantean en dos niveles. En el de las consecuencias que pueden tener las intervenciones genéticas, consecuencias de las que poco se sabe, y que, por lo tanto, sólo son razonables si se pretende con ellas evitar enfermedades graves. En el de la justicia distributiva, que puede profundizar la brecha entre pobres y ricos, al ampliar las desigualdades de educación a desigualdades de herencia. Y en que el límite entre la eugenesia negativa y positiva no podría consistir, por lo dicho, en la idea regulativa del consenso anticipado contrafácticamente, sino tal vez en un desarrollo del enfoque de las capacidades de Sen, que podría constituir un «mínimo antropológico» de empoderamiento, como hemos apuntado en nuestra propuesta de marco ético para la manipulación genética. Un empoderamiento que no debería quedar al juego del mercado en una sociedad justa.

En cualquier caso, y regresando a Huxley, la libertad no se pierde tanto por el condicionamiento genético como por otros dos factores casi infalibles: el soma, la sustancia que permite a los pobladores de mundo feliz alienarse cuando llegan el dolor o la emoción excesiva y sumergirse en un imaginario bienestar, y la hipnopedia, la mentalización incesante que sufren los nuevos seres desde el momento de la fecundación artificial, las palabras repetidas hasta la saciedad sin razonamiento, que constituyen «la mayor fuerza socializadora y moralizadora de todos los tiempos» ${ }^{29}$.

\footnotetext{
${ }^{29}$ Aldous Huxley, Un mundo feliz, p. 53.
} 